\title{
Article \\ Effect of External Impacts on the Structure and Martensitic Transformation of Rapidly Quenched TiNiCu Alloys
}

\author{
Alexander Shelyakov ${ }^{1, *(1)}$, Nikolay Sitnikov ${ }^{1,2}$, Irina Zaletova ${ }^{1,2}$, Natalia Tabachkova ${ }^{3}$ and Nikolay Andreev ${ }^{3}$ \\ 1 National Research Nuclear University MEPhI (Moscow Engineering Physics Institute), Kashirskoe shosse 31, \\ 115409 Moscow, Russia; irina-zaletova@mail.ru \\ 2 JSC SSC "Keldysh Research Center", Onezhskaya st. 8, 125438 Moscow, Russia; sitnikov_nikolay@mail.ru \\ 3 National University of Science and Technology “MISiS", Leninskiy pr. 4, 119049 Moscow, Russia; \\ ntabachkova@misis.ru (N.T.); andreevn.misa@gmail.com (N.A.) \\ * Correspondence: alex-shel@mail.ru
}

check for updates

Citation: Shelyakov, A.; Sitnikov, N.; Zaletova, I.; Tabachkova, N.; Andreev, N. Effect of External Impacts on the Structure and Martensitic Transformation of Rapidly Quenched TiNiCu Alloys. Metals 2021, 11, 1528. https:// doi.org/10.3390/met11101528

Academic Editor: Volodymyr A. Chernenko

Received: 2 September 2021

Accepted: 23 September 2021

Published: 26 September 2021

Publisher's Note: MDPI stays neutral with regard to jurisdictional claims in published maps and institutional affiliations.

Copyright: (C) 2021 by the authors. Licensee MDPI, Basel, Switzerland. This article is an open access article distributed under the terms and conditions of the Creative Commons Attribution (CC BY) license (https:/ / creativecommons.org/licenses/by/ $4.0 /)$.

\begin{abstract}
TiNi-TiCu quasibinary system alloys with a high $\mathrm{Cu}$ content produced by rapid quenching from liquid state in the form of thin amorphous ribbons exhibit pronounced shape memory effect after crystallization and are promising materials for miniaturized and fast operating devices. There is currently no complete clarity of the mechanisms of structure formation during crystallization from the amorphous state that determine the structure-sensitive properties of these alloys. This work deals with the effect of the initial amorphous state structure and crystallization method of the alloys on their structure and phase transformations. To this end the alloy containing 30 at.\% Cu was subjected to thermal and mechanical impact in the amorphous state and crystallized using isothermal or electropulse treatment. We show that after all types of treatment in the amorphous state the structure of the alloy remains almost completely amorphous but the characteristic temperatures and enthalpy of crystallization become slightly lower. Isothermal crystallization of alloy specimens produces a submicrocrystalline structure with an average grain size in the $0.4-1.0 \mu \mathrm{m}$ range whereas electropulse crystallization generates a bimorphic structure consisting of large 4-6 $\mu \mathrm{m}$ grains and 2-3 $\mu \mathrm{m}$ high columnar crystals in the vicinity of the surface. The grains have nanosized plate-like and subgrain structures. The largest grains are observed in thermally activated samples, meanwhile, mechanical impact in the amorphous state leads to the formation of equiaxed finer grains with a less defective subgrain structure and to the shift of the temperature range of the martensitic transformation toward lower temperatures.
\end{abstract}

Keywords: amorphous materials; shape memory alloys; microstructure; martensitic transformation; X-ray techniques; electron microscopy

\section{Introduction}

Alloys exhibiting shape memory effect (SME) are a bright example of the so-called smart functional materials. The rapid development of these materials in recent decades is caused, on the one hand, by the design of efficient processes of their fabrication and, on the other hand, by their excellent combination of physical and chemical properties which provide their wide application in aviation and space technologies [1,2], power industry and device building [3,4], robot engineering [5,6], MEMS technology [7,8], biomedicine and biotechnology [1,4]. The fabrication of miniaturized and fast operating devices on the basis of SME alloys, in particular for MEMS, requires thin materials with a narrow temperature hysteresis. One promising variant of a material which meets the above requirements are alloys of the TiNi-TiCu quasibinary intermetallic system with a copper content of above 10 at.\% [9-12]. However the production of these alloys using conventional metallurgical processes of melting or sintering may cause not only the formation of detrimental Ti-Cu phases which hinder the martensitic transformation (MT) and, as a consequence, reduce shape memory strain, but also embrittle the alloys [13-15]. This problem can be solved 
using the technology of rapid quenching from liquid state which allows obtaining TiNi$\mathrm{TiCu}$ system alloys with a high $\mathrm{Cu}$ content in the form of thin ribbons with a single-phase composition and a homogeneous structure [16,17]. At high cooling rates $\left(10^{6} \mathrm{~K} / \mathrm{s}\right.$ or higher $)$ this technique allows producing amorphous ribbons of 30-50 $\mu \mathrm{m}$ in thickness $[18,19]$ which exhibit the best SME performance after crystallization [19-21]. The conditions of quenching from melt have a strong effect on the structure of the amorphous state as the precursor of crystalline phase formation. It has been shown that an increase in the quenching rate increases the degree of amorphization, i.e., the degree of disorder, thus favoring a significant reduction in the dimensions of the crystallization products given the same morphology and crystalline structure of the material [22]. An increase in the copper content leads to an increase in the amorphization ability of the alloys and hence an improvement of the stability of ribbon geometrical parameters $[17,23]$ but also a reduction of the plasticity of the alloys and their SME parameters after isothermal treatment due to the formation of brittle Ti-Cu phases $[19,23,24]$. In the meantime many studies have shown that the phase composition, morphology and average grain size of TiNi-TiCu system alloys with a high copper content that were crystallized from the amorphous state depend strongly on the crystallization conditions. High-rate annealing (e.g., electropulse or laser treatment) leads to the formation of finer structures as compared with conventional isothermal annealing $[25,26]$.

Nevertheless it was recently showed [27] that after high-rate crystallization of amorphous TiNi-TiCu alloys with a copper content of 25 to 38 at.\% by a single $10 \mathrm{~ms}$ electric current pulse, in contradiction with the above line of reasoning, the alloy structure is not refined in comparison with isothermal treatment results, but on the contrary the average grain size increases significantly. The largest grain size was obtained in the alloy containing 38 at.\% copper which had the greatest amorphization degree at the same quenching speed of $10^{6} \mathrm{~K} / \mathrm{s}$ although, in accordance with the reasons presented above, this factor should favor the formation of the finest structure. The origin of this phenomenon seems to be the fact that crystal growth rate is higher than crystal nucleation rate. This can be caused by a decrease in the number of crystallization centers in the initial amorphous state or by the fact that "frozen-in" crystallization centers do not have a suitable structure. One would expect that the formation of additional crystallization centers in the alloys can be stimulated by thermal and/or mechanical impact in the amorphous state.

Thus, there is currently no clarity of the mechanisms of multiple processes with the key role in understanding of the structure formation conditions during crystallization from the amorphous state and determining the structure-sensitive properties of the alloys. For instance there is no complete understanding of the role of the amorphous phase in the formation and decomposition of the crystalline structure. The aim of this work is to study the effect of the initial amorphous structure, thermal and/or mechanical impact in the amorphous state and crystallization conditions of rapidly quenched quasibinary TiNi-TiCu system alloys with a high copper content on the structure formation processes and martensitic transformation behavior.

\section{Materials and Methods}

For the study, melt-spun ribbons from an alloy of the TiNi-TiCu system with a copper content of 30 at.\%, which is the limit of copper solubility in TiNi, were selected. Presynthesized $\mathrm{Ti}_{50} \mathrm{Ni}_{20} \mathrm{Cu}_{30}$ (at.\%) alloys were prepared from the high purity metals by melting six times in an argon arc furnace. Then the obtained ingots were re-molten in quartz crucibles under a purified helium atmosphere and ejected through a $0.4 \mathrm{~mm}$-wide slot nozzle in the crucible on the outer surface of a rapidly rotating wheel made of copper. Therefore, the ribbons with a thickness of around $40 \mu \mathrm{m}$ were produced by the planar flow casting technique at a melt cooling rate of about $10^{6} \mathrm{~K} / \mathrm{s}$ [17].

For understanding the effect of thermal and mechanical impact of the alloys in the amorphous state on the nucleation processes and crystal growth rate during subsequent crystallization and eventually on the formation of the crystalline structure of the alloys, melt-spun ribbons (hereinafter denoted as $30 \mathrm{~A}$ ) were subjected to the following treatment: 
- $\quad$ external tensile stress along the ribbon at up to $900 \mathrm{MPa}$ (the respective specimen is denoted as $30 \mathrm{~A}+\mathrm{P})$;

- isothermal annealing at a constant temperature of $350{ }^{\circ} \mathrm{C}$ (below the glass transition temperature) for $600 \mathrm{~s}$ (specimen 30A + T);

- sequential exposure to isothermal annealing and tensile stress (specimen $30 \mathrm{~A}+\mathrm{T}+\mathrm{P}$ ). Thus, using the above described thermal and deformation treatment techniques we obtained a series of experimental specimens with different treatment parameters.

The alloys were crystallized by two methods: isothermal annealing at $500{ }^{\circ} \mathrm{C}$ for $300 \mathrm{~s}$ and electropulse method, i.e., passing a short electric current pulse with preset duration and amplitude through the specimen for its heating to the specified temperature due to Joule heat release. To calculate the required parameters of electropulse crystallization of the amorphous specimens we used the current density to electric pulse duration relationship derived in [28].

For the metallographic study of ribbon specimens we prepared their cross-sections using Buehler equipment (Buehler, An ITW Company, Lake Bluff, IL, USA). Final polishing was conducted using an acid-containing mixed suspension with an abrasive grain size of $50 \mathrm{~nm}$. The cross-section microstructure of the specimens was studied under a FEI Quanta 600 FEG (Thermo Fisher Scientific Inc., Hillsboro, OR, USA) scanning electron microscope (SEM). The elemental composition of the specimens was controlled using energy dispersion X-ray spectroscopy (EDS) in SEM studies.

The fine structure of the alloys was investigated under a JEOL JEM 2100 (JEOL Ltd., Tokyo, Japan) transmission electron microscope (TEM). The specimens for the TEM study were fabricated using the focused ion beam (FIB) technique by means of an FEI Strata 201 FIB setup (Thermo Fisher Scientific Inc., Hillsboro, OR, USA) equipped with an Omniprobe $^{\circledR}$ (Oxford Instruments plc, High Wycombe, UK) nanomanipulator (Figure 1). The FIB technique allows precision ion beam etching and polishing based on local sputtering of the material with the ion beam. This provides for selective cutting of micron-sized specimens out of materials, removal with the nanomanipulator and transfer to the required place, e.g., on the TEM grid. Specimens fabricated using this technique significantly broaden the potentialities of TEM studies by providing the possibility of analyzing strongly localized structures.
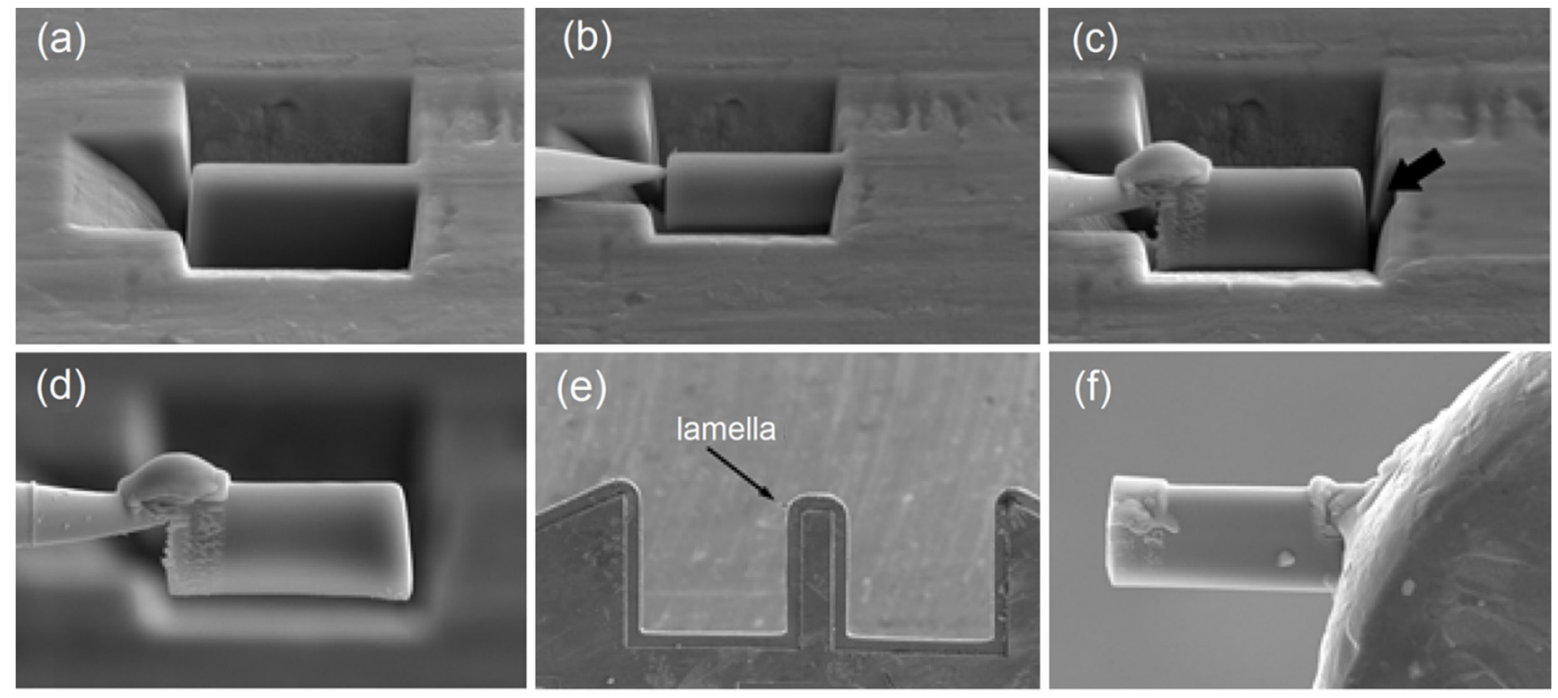

Figure 1. TEM specimen preparation operation sequence using FIB: (a) lamella appearance under microscope, (b) nanomanipulator needle brought to the lamella, (c) needle fastening to the lamella by platinum deposition and lamella cutting from the ribbon (shown by arrow), (d) lamella removal from the etching pit and movement, (e) lamella attachment (welding) to Omniprobe ${ }^{\circledR}$ lift-out grid and (f) magnified image of lamella ready for thinning. 
X-ray diffraction analysis was carried out with Bragg-Brentano focusing and a hybrid monochromator on a PANalytical Empyrean (Malvern Panalytical plc, Malvern, UK) X-ray diffractometer in $\mathrm{Cu}-\mathrm{K}_{\alpha}$ radiation.

The temperature ranges and enthalpy of both crystallization and martensitic transformation in the alloys were determined using differential scanning calorimetry (DSC) on an STA 449 F1 Jupiter (Erich NETZSCH GmbH \& Co. Holding KG, Selb, Germany) calorimeter by heating and cooling cycles in the 20 to $600{ }^{\circ} \mathrm{C}$ range with $10^{\circ} \mathrm{C} / \mathrm{min}$ rate and in the 20 to $100^{\circ} \mathrm{C}$ range with $2.5^{\circ} \mathrm{C} / \mathrm{min}$ rate, respectively.

\section{Results}

The structure, martensitic transformation and shape memory behavior of TiNi-based alloys are known to depend essentially on their chemical composition. To visualize and analyze the cross-sections of the ribbons we studied their images in topographic and composition contrast at different magnifications in SEM studies. Typical appearances of the EDS data are shown in Figure 2. Quantitative and qualitative analyses of the elemental composition of the specimens were carried out locally and in selected areas (Figure 2a) for which the typical spectral patterns are shown (Figure 2b). Furthermore, we obtained linear profiles (Figure 2c) and multi-spectral maps (Figure 2d) of elemental distribution. The results of the study show that the elemental composition of all the amorphous specimens is the same as the composition of the initial ingot within the method accuracy.
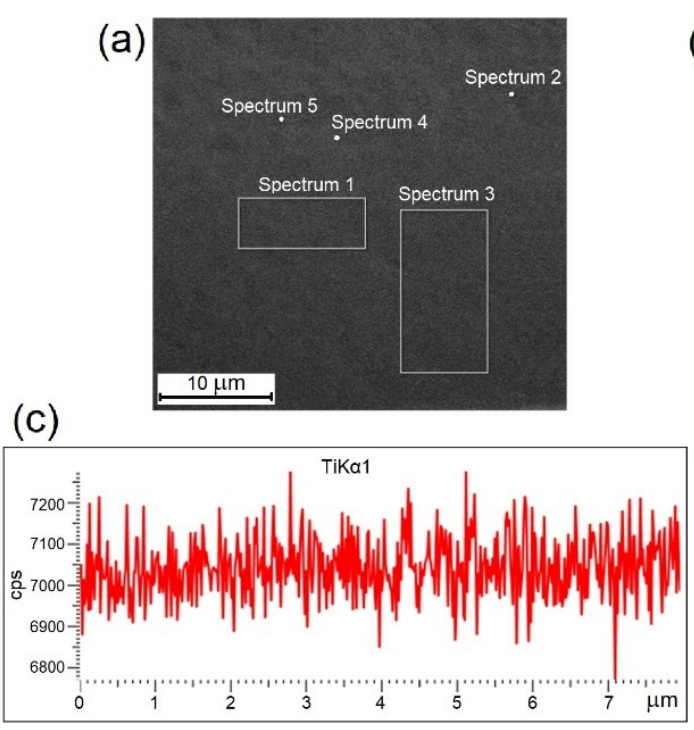

(b)

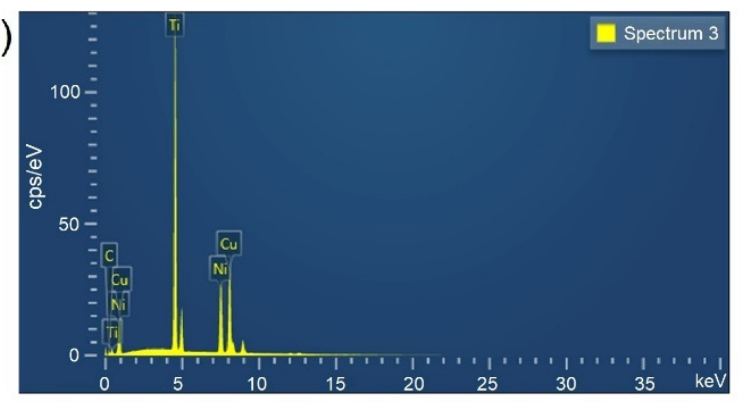

(d)

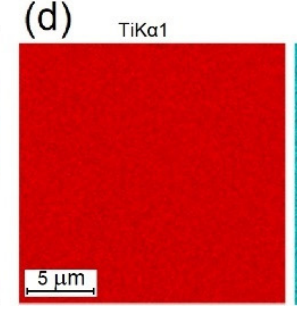

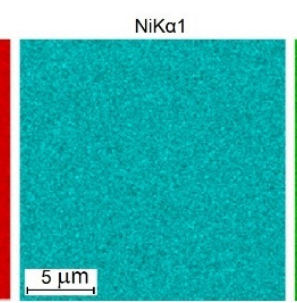

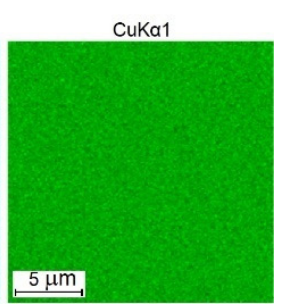

Figure 2. Typical appearance of experimental EDS data for 30A specimen: (a) selected areas of specimen, (b) energy spectrum, (c) linear profile and (d) multi-spectral maps.

The electron microscopic studies of the specimen cross-sections within the SEM resolution limitations did not reveal any structural elements, including crystallites, either on the surface or in the bulk of the ribbon in the as-quenched state (Figure 3a) as well as after thermal and mechanical impact (Figure 3b-d), i.e., the SEM images showed a completely amorphous structure of melt-spun ribbons from the alloy of the TiNi-TiCu system with a copper content of 30 at.\%. The X-ray diffraction patterns of all the specimens show a smeared amorphous halo at $2 \theta=39-45$ deg (Figure $4 a$ ) which also indicates that the ribbons are amorphous. Nevertheless the alloy specimens after thermal and mechanical impact in the amorphous state exhibit weak peaks of a crystalline phase which cannot be definitely identified due to the low intensity and small number of diffraction lines. 

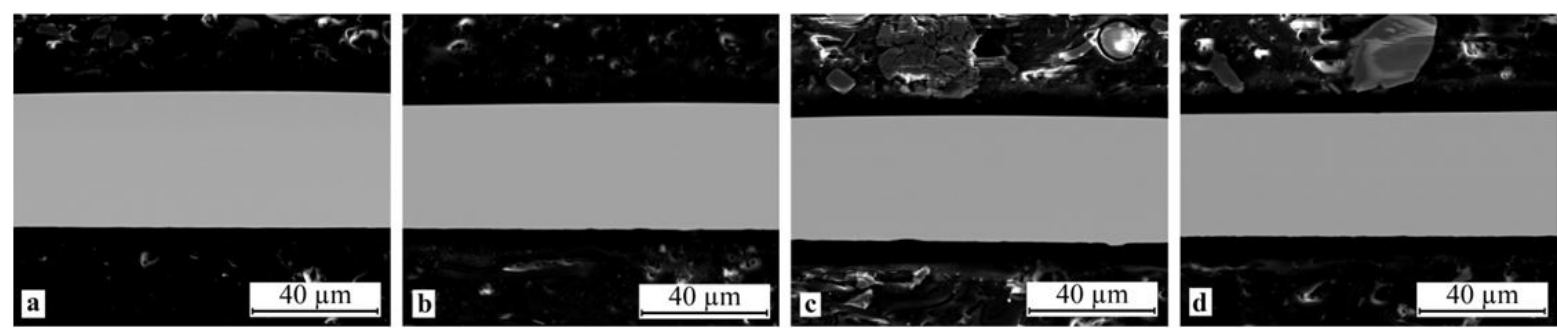

Figure 3. Typical SEM images of specimen cross-sections in the initial as-quenched condition and after mechanical and thermal treatment: (a) 30A, (b) 30A + P, (c) 30A + T and (d) $30 \mathrm{~A}+\mathrm{T}+\mathrm{P}$.
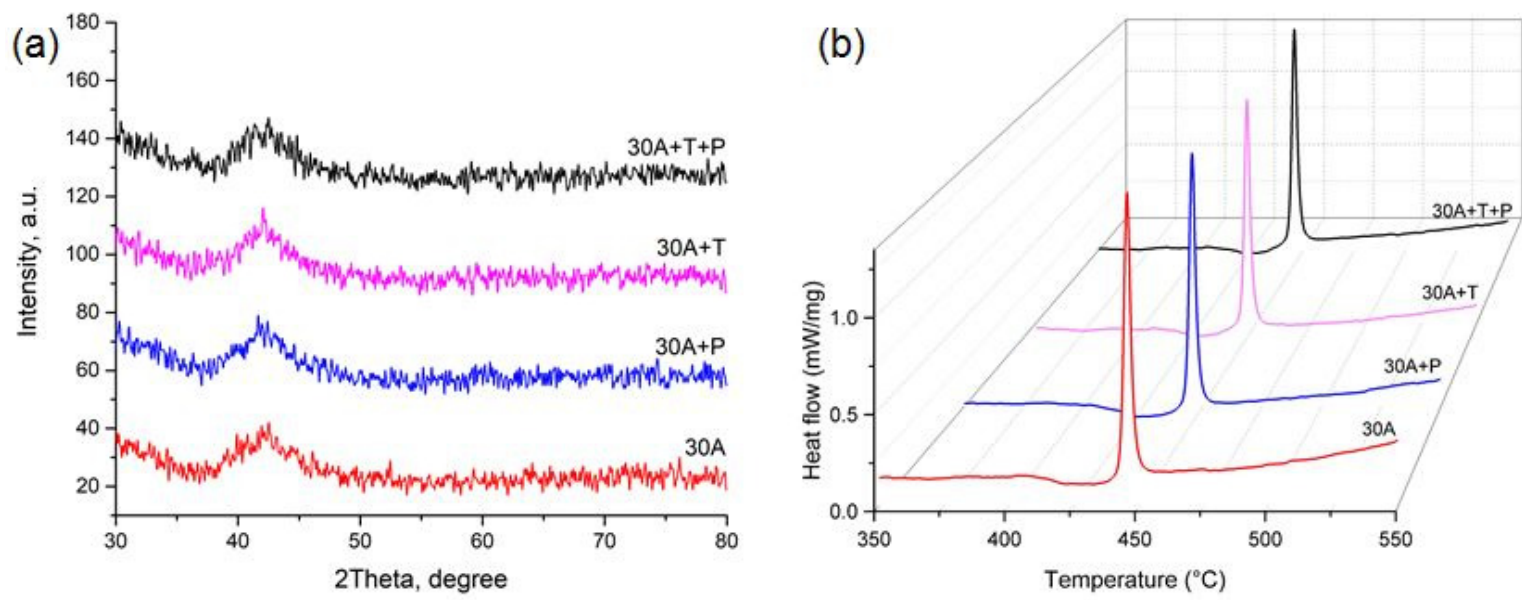

Figure 4. (a) X-ray diffraction patterns and (b) DSC curve of crystallization for specimen in the initial as-quenched condition and after mechanical and thermal impact.

To understand the crystallization mechanisms of the amorphous ribbons we determined the characteristic temperatures and enthalpies of crystallization using the DSC method. As can be seen from the DSC curves (Figure $4 b$ ) heating of the specimens produces a strong thermal effect of single-stage crystallization which is specific of polymorphous crystallization typically occurring in thin TiNiCu ribbons and films [24,29]. A polymorphic transformation includes the growth of one crystalline phase $B 2$ with the same composition as the amorphous matrix. The glass transition temperature $T_{g}$ and crystallization peak temperature $\mathrm{T}_{\mathrm{p}}$ and the crystallization enthalpy $\mathrm{H}_{\mathrm{Cr}}$ determined from these dependences are summarized in Table 1. It can be seen that isothermal annealing and tensile deformation in the amorphous state reduce the thermal effect of crystallization $\mathrm{H}_{\mathrm{cr}}$ by $4-5 \%$ and noticeably decrease $\mathrm{T}_{\mathrm{g}}$ and $\mathrm{T}_{\mathrm{p}}\left(\right.$ by $5-6{ }^{\circ} \mathrm{C}$ ).

Table 1. Characteristic temperatures and enthalpy of specimen crystallization.

\begin{tabular}{cccc}
\hline Specimen & $\mathbf{T}_{\mathbf{g}},{ }^{\circ} \mathbf{C}$ & $\mathbf{T}_{\mathbf{p}},{ }^{\circ} \mathbf{C}$ & $\mathbf{H}_{\mathbf{c r}}, \mathbf{J} / \mathbf{g}$ \\
\hline $30 \mathrm{~A}$ & 406,5 & 428,0 & 30,19 \\
$30 \mathrm{~A}+\mathrm{P}$ & 402,7 & 422,4 & 29,40 \\
$30 \mathrm{~A}+\mathrm{T}$ & 401,1 & 421,7 & 29,99 \\
$30 \mathrm{~A}+\mathrm{T}+\mathrm{P}$ & 402,7 & 422,9 & 29,36 \\
\hline
\end{tabular}

TEM study of the specimen fine structure revealed an ultrafine absorption contrast typical of amorphous phases in all the alloy specimens, both initial as-quenched and after mechanical or thermal treatment. Typical appearance of 30A specimen (lamella) for TEM after thinning and polishing and typical bright-field TEM images are shown in Figure 5. The respective electron diffraction patterns show several diffuse rings the intensity of which decreases with an increase in the diffraction vector angle. 

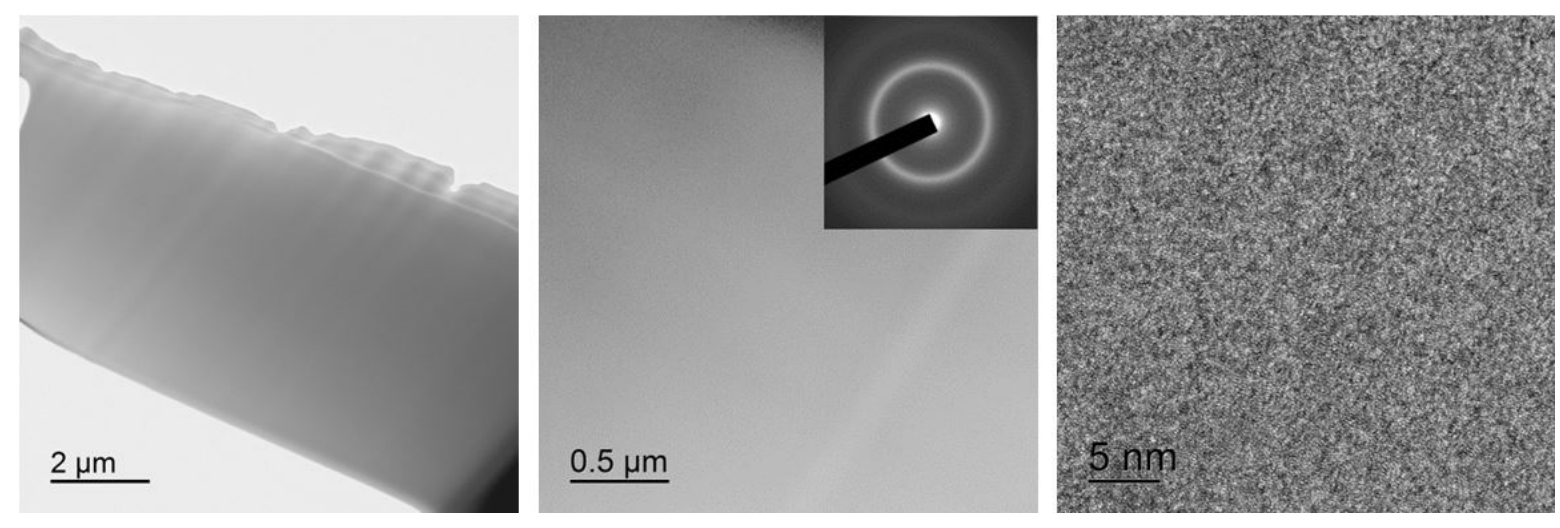

Figure 5. Bright-field TEM images with a selected area electron diffraction pattern (SAED) for 30A specimen.

Then we carried out dynamical (high-rate) crystallization of the specimens as-quenched and after treatment in the amorphous state using electropulse heat treatment (EP) with a pulse duration of $10 \mathrm{~ms}$. For comparison we fabricated ribbon specimens crystallized by isothermal annealing (IT) in air at $500{ }^{\circ} \mathrm{C}$ for $300 \mathrm{~s}$.

X-ray study of the specimen structure showed that all the specimens after isothermal and electropulse crystallization have the $B 19$ martensitic structure at room temperature which is in agreement with earlier data $[22,23,27]$. One can however note that the intensity of the $B 19$ phase reflections in the diffraction patterns of the dynamically crystallized specimens both in the initial and in the activated amorphous states is slightly higher as compared with that of the isothermally crystallized specimens (Figure 6). Specimen heating to above the $A_{f}$ temperature leads to the reverse $B 19 \rightarrow B 2$ martensitic transformation (MT) resulting in the formation of an austenitic state characterized by intense $B 2$ phase peaks (Figure 7).

SEM study of the crystallized specimen cross-sections showed that isothermal crystallization of the alloy leads to the formation of a submicrocrystalline structure with an average grain size of $0.4-1.0 \mu \mathrm{m}$ (Figure 8). One should however bear in mind that mechanical impact in the amorphous state leads to the formation of a structure with the smallest grain size (Figure 8b). One can also note the relatively high homogeneity of the structure, for example one can observe but a slight fraction of columnar crystals in the vicinity of the surface. In the meantime electropulse crystallization dramatically changes the morphology of the alloy structure: a bimorphic structure forms consisting of large 4-6 $\mu \mathrm{m}$ grains and 2-3 $\mu \mathrm{m}$ high columnar crystals near the surface (Figure 9). The large crystals have a subgrain structure which can be poorly resolved by SEM. The results of the study show that treatment in the amorphous state does not produce tangible changes in the structure.

TEM study of the fine structure of the specimens confirmed that isothermal crystallization leads to the formation of a submicrocrystalline structure with a grain size of $0.4-1.0 \mu \mathrm{m}$ with plate-like and subgrain internal structures typical of martensite (Figure 10). The sizes of the martensite plates $(20-80 \mathrm{~nm})$ and the subgrain structure of the $30 \mathrm{~A}+\mathrm{IT}$ and $30 \mathrm{~A}+\mathrm{T}$ $+\mathrm{P}+\mathrm{IT}$ specimens are quite similar but the grain size in the $30 \mathrm{~A}+\mathrm{T}+\mathrm{P}+\mathrm{IT}$ specimen (Figure 10c) is greater than in the 30A + IT one (Figure 10a). The grain structure is finer in the $30 \mathrm{~A}+\mathrm{P}+\mathrm{IT}$ specimen (Figure 10b) where the internal structure of the grains is less defective, the subgrain boundaries are clearly resolvable, and the martensite plates are larger than those in the $30 \mathrm{~A}+\mathrm{IT}$ and $30 \mathrm{~A}+\mathrm{T}+\mathrm{P}+\mathrm{IT}$ specimens. The SAED studied correspond to the $B 19$ martensitic structure without $B 2$ austenite. All the SAED patterns are typical of polycrystalline structures with a well-developed subgrain structure. 

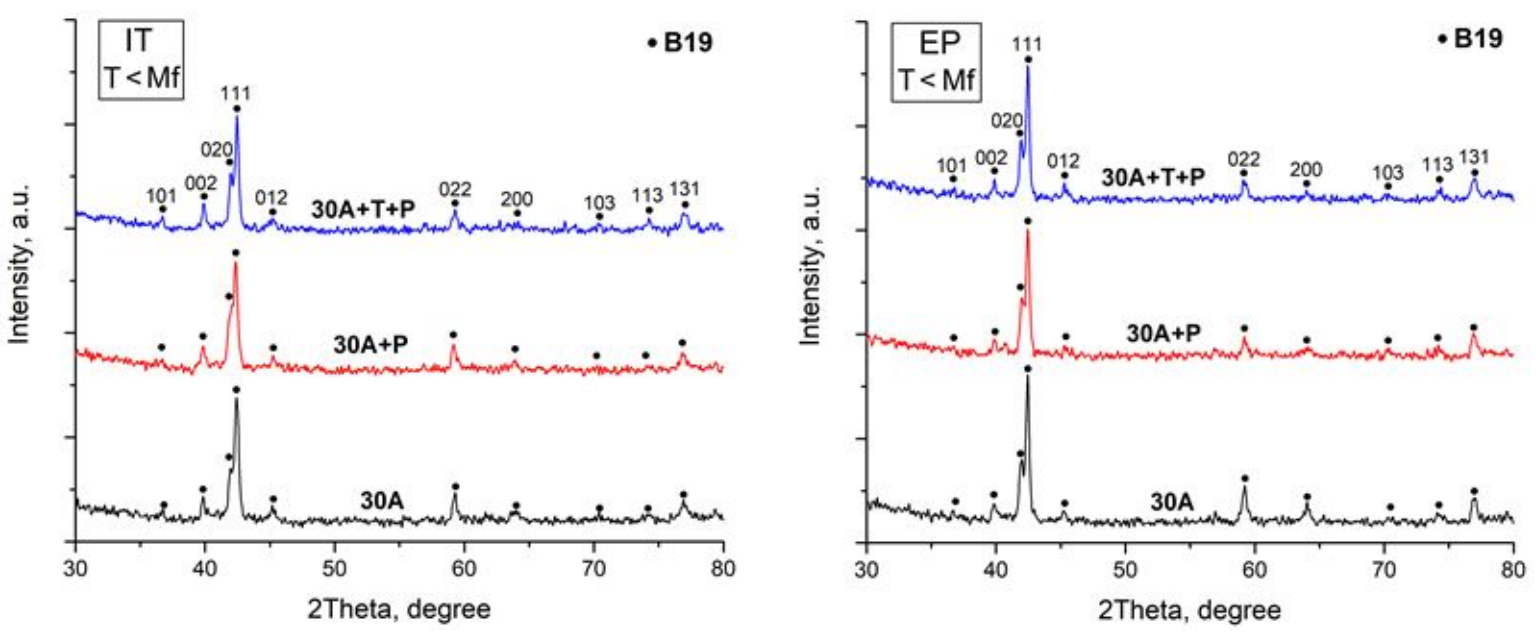

Figure 6. X-ray diffraction patterns of specimens after isothermal heat treatment (IT) and after electropulse crystallization (EP) for $10 \mathrm{~ms}$ (martensitic state).
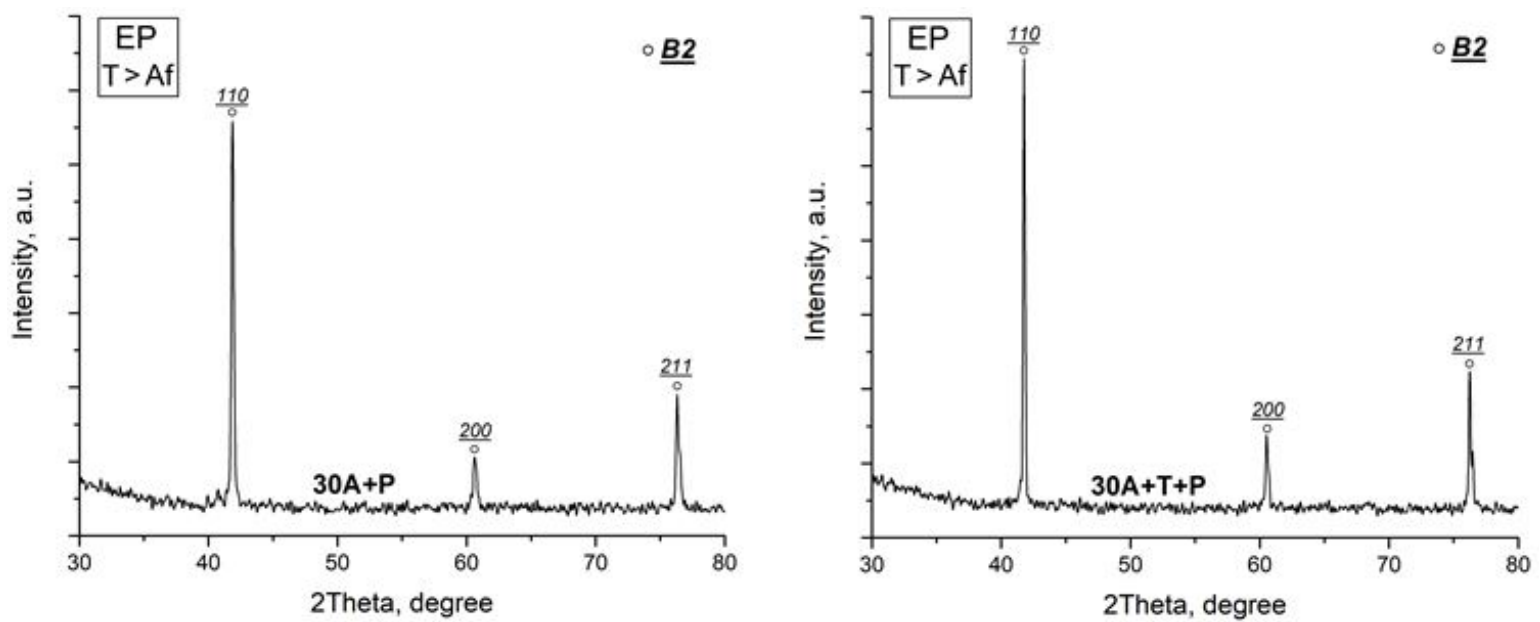

Figure 7. X-ray diffraction patterns of specimens after isothermal heat treatment (IT) and after electropulse crystallization (EP) for $10 \mathrm{~ms}$ (austenitic state).
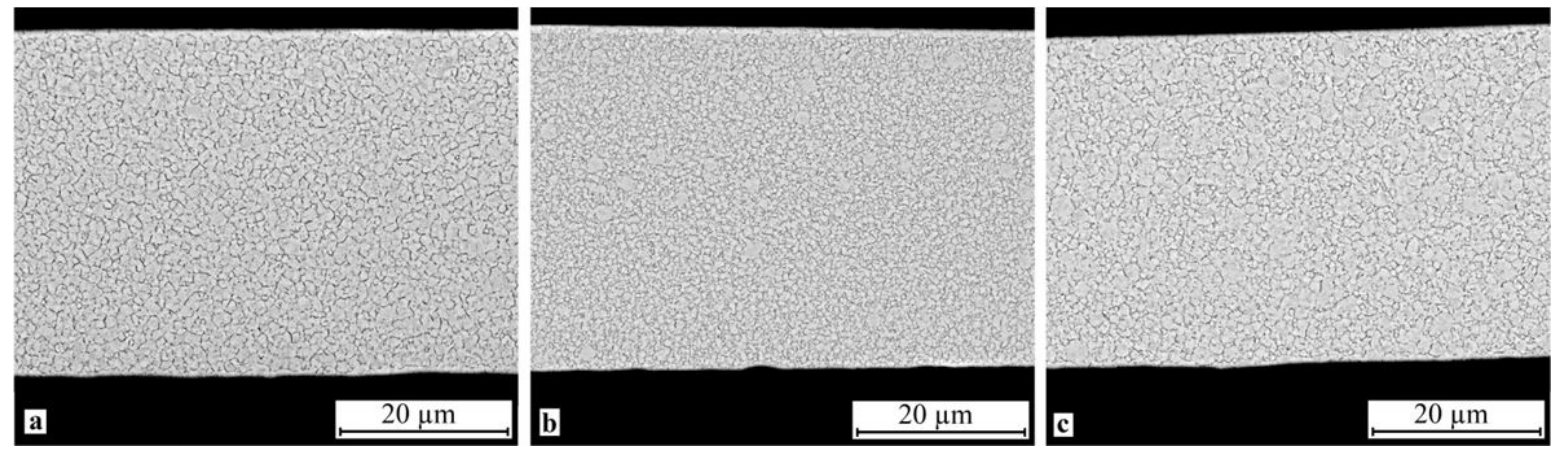

Figure 8. Microstructure of specimen cross-section after isothermal crystallization: (a) $30 \mathrm{~A}+\mathrm{IT}$, (b) $30 \mathrm{~A}+\mathrm{P}+\mathrm{IT}$ and (c) $30 \mathrm{~A}$ $+\mathrm{T}+\mathrm{P}+\mathrm{IT}$ 

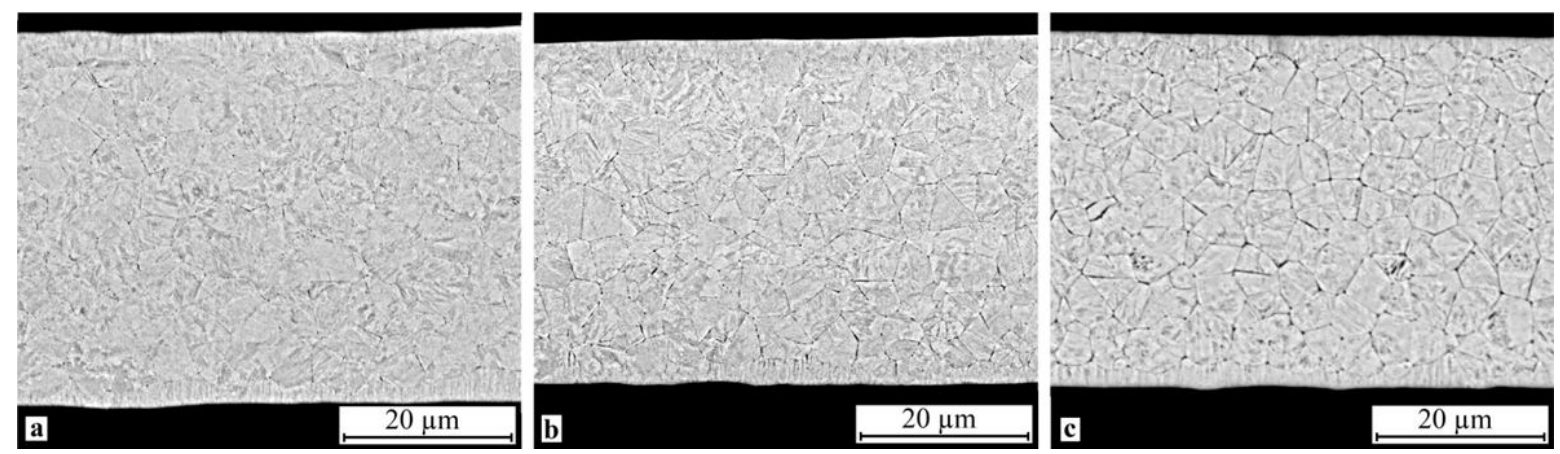

Figure 9. Microstructure of specimen cross-section after electropulse crystallization for $10 \mathrm{~ms}$ : (a) $30 \mathrm{~A}+\mathrm{EP},(\mathbf{b}) 30 \mathrm{~A}+\mathrm{P}+$ EP and (c) $30 \mathrm{~A}+\mathrm{T}+\mathrm{P}+\mathrm{EP}$.
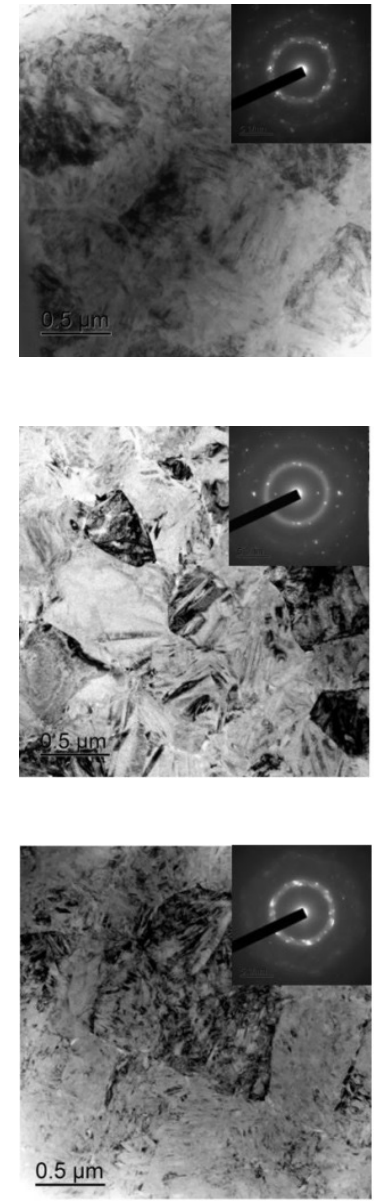

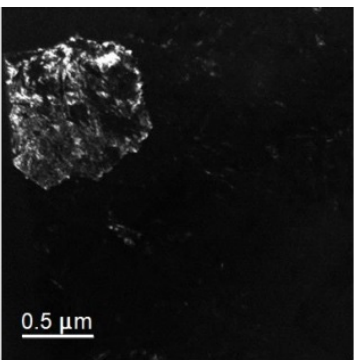

(a)

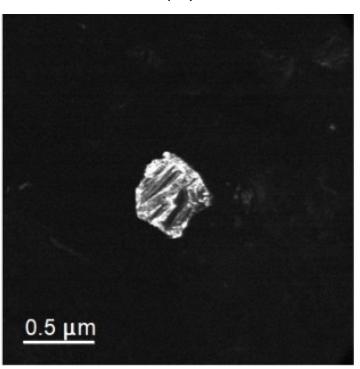

(b)

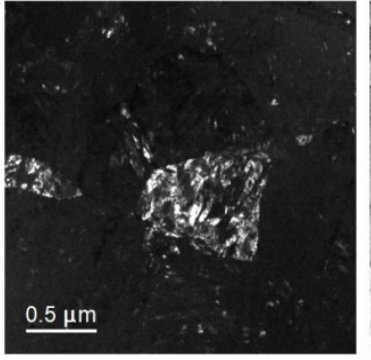

(c)
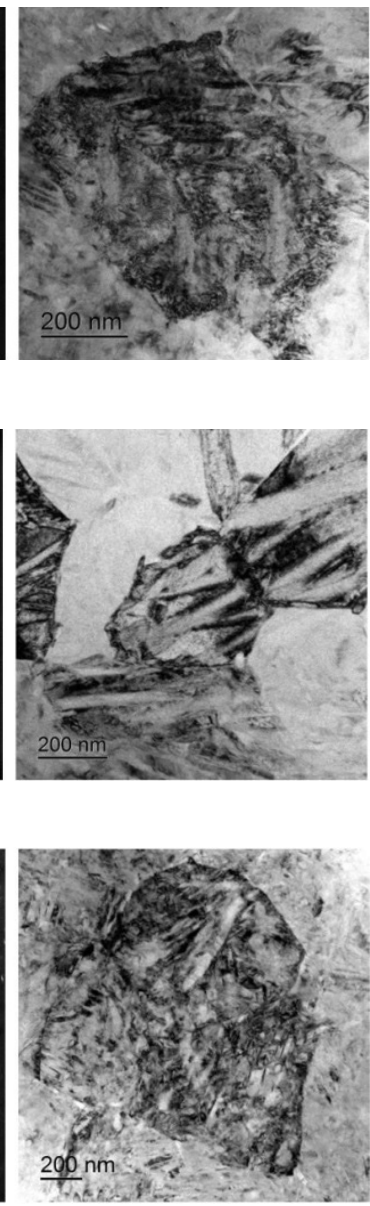

Figure 10. Dark- and bright-field TEM micrographs and respective SAED pattern of specimens after isothermal crystallization: (a) 30A + IT, (b) $30 \mathrm{~A}+\mathrm{P}+\mathrm{IT}$ and (c) $30 \mathrm{~A}+\mathrm{T}+\mathrm{P}+\mathrm{IT}$.

As can be seen from Figure 11, electropulse treatment of the specimens provides for noticeably larger grain sizes as compared with isothermal treatment. The 30A + P + EP specimen which was subjected to tensile treatment in the amorphous state (Figure 11b) has finer and more equiaxed grains compared with the other specimens. The largest grains and the widest martensite plates are in the $30 \mathrm{~A}+\mathrm{T}+\mathrm{EP}$ specimen which was thermally treated in the amorphous state (Figure 11c). The 30A + EP (Figure 11a) and 30A + T + P + EP specimens have wider martensite plates but a more defective internal structure of the grains than for the 30A + T + EP specimen. By analogy with the isothermal crystallized specimens, there are clearer martensite plates, subgrain boundaries and grain boundaries 
in the 30A + P + EP specimen, all its SAED patterns are typical of polycrystalline materials with a $B 19$ structure and a well-developed subgrain structure.
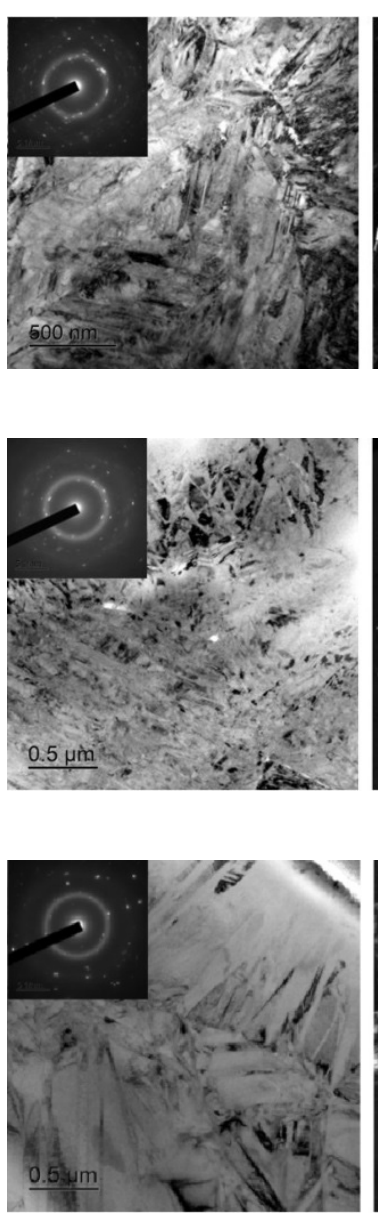
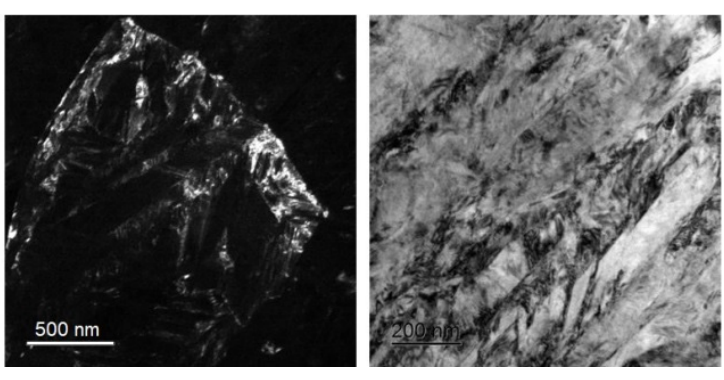

(a)
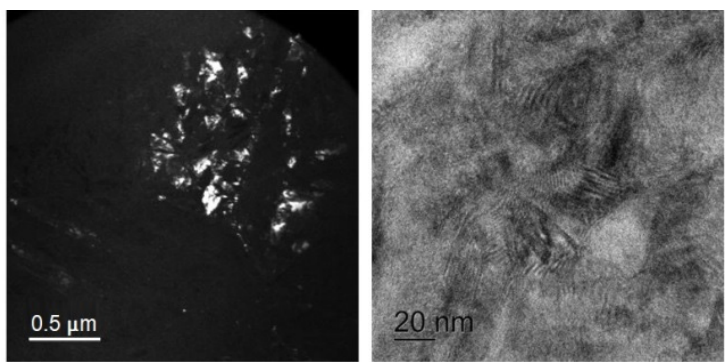

(b)
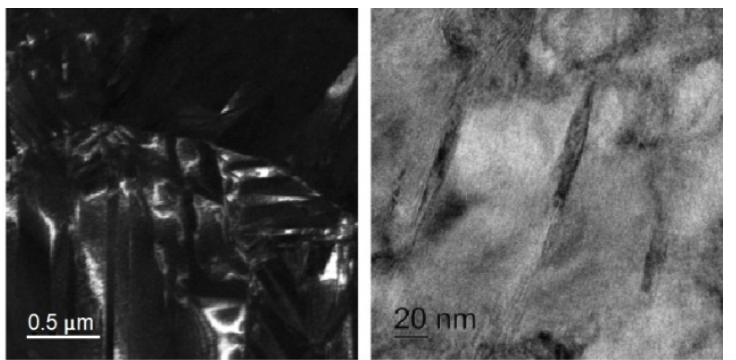

(c)

Figure 11. Dark- and bright-field TEM micrographs and respective SAED pattern of specimens after electropulse crystallization: (a) $30 \mathrm{~A}+\mathrm{EP}$, (b) $30 \mathrm{~A}+\mathrm{P}+\mathrm{EP}$ and (c) $30 \mathrm{~A}+\mathrm{T}+\mathrm{EP}$.

To understand the correlation between the structural features of the specimens and MT behavior we studied the specimens using the DSC method. The DSC curves are shown in Figures 12 and 13 and the start and finish temperatures of the direct and reverse MT $\left(M_{s}, M_{f}, A_{s}\right.$ and $A_{f}$, respectively) and the transformation enthalpies $H_{M}$, and $H_{A}$ derived from the curves are summarized in Table 2. Comparison of the DSC data for the specimens after isothermal and electropulse crystallization shows that both the heat treatment modes lead to single-stage heat release and absorption peaks but the transformation enthalpy is greater for electropulse treatment. These data are in agreement with the higher intensity of the B19 phase reflections in the X-ray diffraction patterns for this treatment method (Figure 6). The MT temperature range in the dynamically crystallized specimens is shifted toward higher temperatures possibly due to the noticeably larger grain sizes. The critical MT temperatures for the $30 \mathrm{~A}+\mathrm{P}+\mathrm{IT}$ specimen which was subjected to tensile deformation in the amorphous state are significantly lower than in the other specimens. This can be caused by the smaller grain sizes and the less defective internal structure of the grains in that specimen (Figure 10b). 

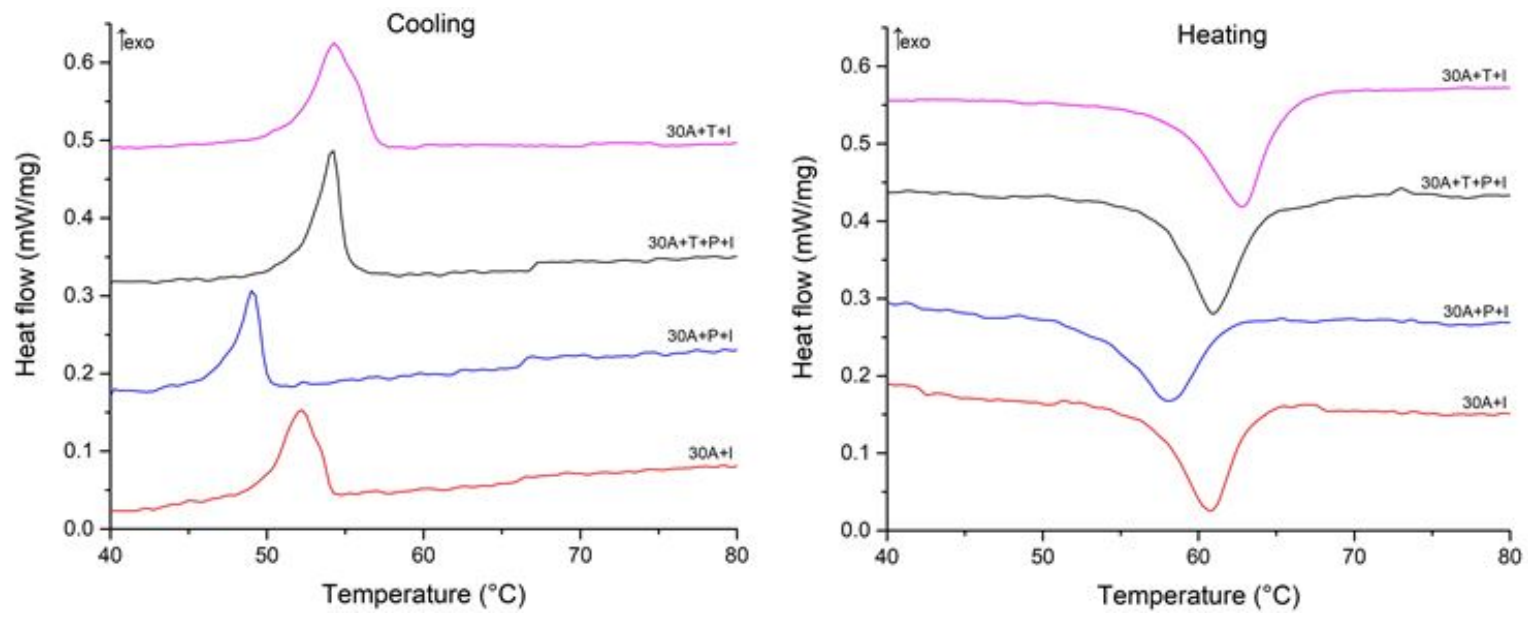

Figure 12. Cooling and heating DSC curves of specimens after isothermal crystallization.
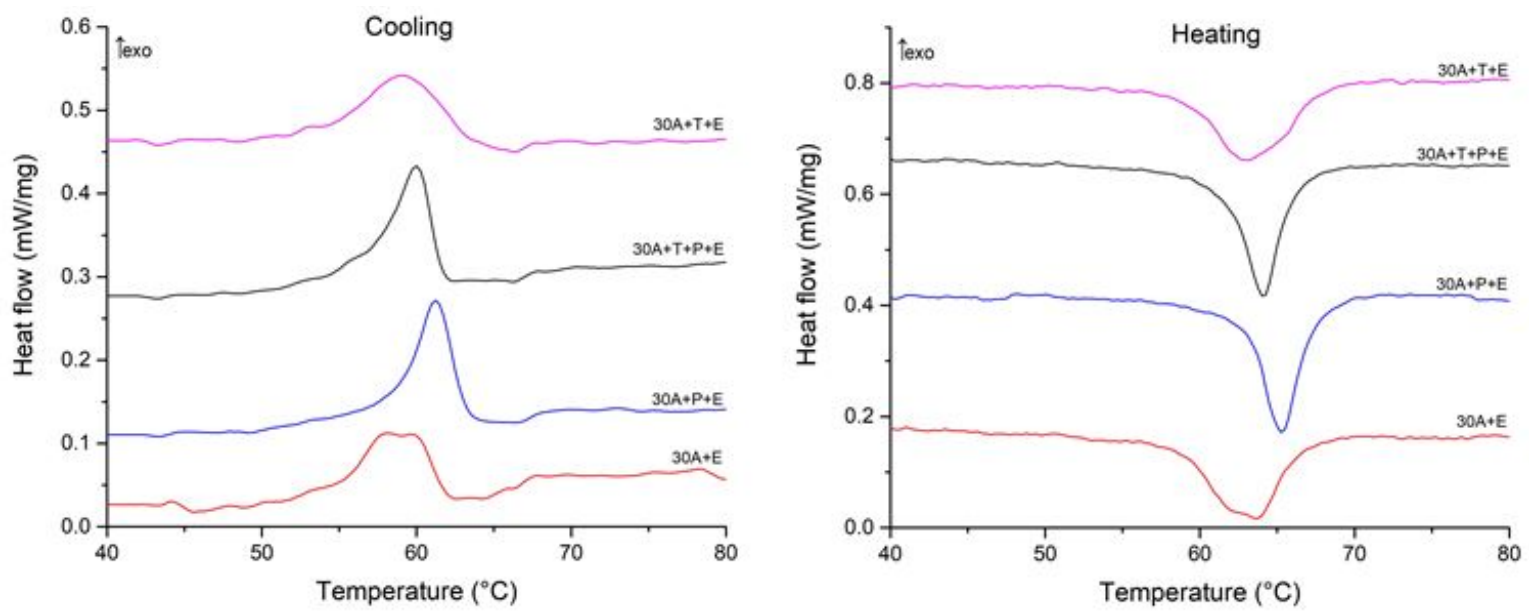

Figure 13. Cooling and heating DSC curves of specimens after electropulse crystallization for $10 \mathrm{~ms}$.

Table 2. MT temperatures and enthalpies for specimens after isothermal and electropulse crystallization.

\begin{tabular}{ccccccc}
\hline Specimen & $\mathbf{M}_{\mathbf{s}},{ }^{\circ} \mathbf{C}$ & $\mathbf{M}_{\mathbf{f}},{ }^{\circ} \mathbf{C}$ & $\mathbf{A}_{\mathbf{s}},{ }^{\circ} \mathbf{C}$ & $\mathbf{A}_{\mathbf{f}},{ }^{\circ} \mathbf{C}$ & $\mathbf{H}_{\mathbf{M}}, \mathbf{J} / \mathbf{g}$ & $\mathbf{H}_{\mathbf{A}}, \mathbf{J} / \mathbf{g}$ \\
\hline 30A + IT & 55,2 & 48,8 & 54,3 & 65,6 & 7,73 & $-6,95$ \\
30A + P + IT & 51,4 & 46,4 & 50,9 & 63,0 & 6,57 & $-6,49$ \\
30A + T + IT & 57,8 & 48,8 & 53,2 & 68,7 & 9,37 & $-8,70$ \\
30A + T + P + IT & 56,5 & 49,8 & 55,2 & 65,6 & 8,20 & $-6,60$ \\
30A + EP & 62,3 & 54,3 & 56,9 & 68,6 & 7,26 & $-8,59$ \\
30A + P + EP & 63,8 & 56,7 & 60,3 & 70,2 & 8,22 & $-8,49$ \\
30A + T + EP & 63,9 & 53,4 & 56,7 & 70,1 & 9,06 & $-9,41$ \\
30 A + T + P + EP & 61,8 & 54,2 & 58,6 & 69,7 & 8,79 & $-8,66$ \\
\hline
\end{tabular}

\section{Discussion}

The structural studies carried out in this work using electron microscopy and X-ray diffraction showed a completely amorphous structure of the quasibinary TiNi-TiCu system alloy containing 30 at.\% $\mathrm{Cu}$ in the as-quenched state. This suggests that as a result of TiNi doping with a large quantity of copper the alloy cooling rate $\left(10^{6} \mathrm{~K} / \mathrm{s}\right)$ achieved in the planar flow casting method used is above the critical cooling rate which is sufficient for suppressing alloy crystallization during cooling and hence providing for its amorphization.

Thermal and mechanical treatment of amorphous alloys is known to produce different structural changes [30]. Isothermal annealing at below $\mathrm{T}_{\mathrm{g}}$ as was the case in this work causes structural relaxation which in turn reduces structural inhomogeneity and drives 
the structure to a glass-like metastable state but does not initiate crystallization. On the contrary, the parameters of mechanical treatment of amorphous ribbon specimens (low (room) temperature and large tensile stress) seem to favor inhomogeneous plastic deformation in the amorphous state which according to different models may occur as the migration of quasi-dislocations [31] or as the movement of free space regions i.e., not linear but point defects [32,33]. Inhomogeneous deformation is but slightly sensitive to load rate, is accompanied by only little strain hardening and unlike homogeneous deformation it reduces the degree of atomic order in the amorphous structure.

The experimental results for rapidly quenched ribbons after thermal and mechanical treatment in the amorphous state showed that the alloy structure remains almost completely amorphous although the X-ray diffraction patterns have weak crystalline phase peaks which may indicate the presence of a small fraction of crystallites in the amorphous matrix. Unfortunately it was not possible to definitely identify the crystalline phase due to the low intensity and small number of the diffraction lines.

The experimental DSC data on the characteristic temperatures and enthalpies of specimen crystallization from the amorphous state confirm the possibility of the formation of a crystalline structure in the amorphous phase. The data obtained show that isothermal annealing and tensile deformation in the amorphous state reduce the thermal effect of crystallization $\mathrm{H}_{\mathrm{Cr}}$ by $4-5 \%$ and tangibly reduce $\mathrm{T}_{\mathrm{g}}$ and $\mathrm{T}_{\mathrm{p}}$ (by $5-6^{\circ} \mathrm{C}$ ). This suggests that alloy treatment in the amorphous state can accelerate crystallization by reducing its activation energy and produces regions in which crystallization may occur at lower temperatures.

Then we studied the effect of the amorphous state "activated" by the thermal and mechanical treatment on the crystalline structure formed by two methods: isothermal annealing at $500{ }^{\circ} \mathrm{C}$ for $300 \mathrm{~s}[22,23]$ and electropulsing with passing a single electric current pulse with preset duration of $10 \mathrm{~ms}$ [27]. It is well known that the crystallization of an amorphous state is a complex process accompanied by competing mechanisms of the nucleation and growth of various crystalline phases under permanently changing conditions of the chemical environment of atoms in transformation regions [30]. It was shown earlier that the phase composition, morphology and average grain size of TiNiTiCu system alloys with a high copper content that were crystallized from the amorphous state depend strongly on the crystallization conditions [18,19,25-27]. Crystallization by high-rate heating (e.g., electropulse or laser treatment) leads to the formation of finer structures as compared with conventional isothermal annealing. In the meantime there is a strong influence of the conditions of quenching from the melt which form the amorphous state as the precursor of crystalline phase formation. The crystallization of amorphous alloys typically occurs under the conditions of large driving forces and low diffusion mobilities. These conditions are more favorable for crystal nucleation than for crystal growth. Further taking into account that the source amorphous phase is homogeneous it is probably reasonable to expect that crystallization will be extremely favorable for the formation of a homogeneous ultrafine-grained structure.

The experimental data show that isothermal crystallization of the alloys both in the initial and activated amorphous states produces a sufficiently homogeneous submicrocrystalline structure with an average grain size of about $0.4-1.0 \mu \mathrm{m}$ with nanosized plate-like and subgrain structures (Figures 8 and 10). One should however note that mechanical treatment in the amorphous state produces a structure with a smaller grain size (Figure $8 b$ ) where the internal grain structure is less defective and has clear subgrain boundaries (Figure 10b). In the meantime electropulse crystallization dramatically changes the morphology of the alloy structure by producing a bimorphic structure of large 4-6 $\mu \mathrm{m}$ sized grains and 2-3 $\mu \mathrm{m}$ high columnar crystals in the vicinity of the surface (Figure 9) with the large crystals with a subgrain structure (Figure 11). The specimen which was subjected to tensile stress in the amorphous state has finer and more equiaxed grains compared with the other specimens. The largest grains and the widest martensite plates are in the specimen which was thermally treated in the amorphous state. 
Thus, heat pre-treatment in the amorphous state before crystallization treatment provides specimens with larger grain sizes whereas mechanical treatment in the amorphous state produces equiaxed and finer grains as compared with other treatment types. The internal subgrain structure is finer in the specimens which were subjected to tensile treatment in the amorphous state.

Diffraction methods showed that all the test specimens after isothermal and electropulse crystallization have a crystalline structure which can be seen in X-ray diffraction patterns and TEM SAED patterns, this structure corresponding to the rhombic martensite phase $B 19$ which is typical of TiNiCu alloys with a high copper content [22-24,27]. Heating to $80^{\circ} \mathrm{C}$ leads to the reverse $\mathrm{B} 19 \rightarrow B 2$ martensitic transformation (MT) with the formation of the $B 2$ austenite phase. The diffraction patterns of the specimens vary but slightly for different specimen fabrication techniques. One can only mention that the intensity of the $B 19$ phase reflections in the $\mathrm{X}$-ray diffraction patterns of the specimens which were subjected to dynamical crystallization both in the initial and the activated amorphous states is slightly higher compared with that for isothermally crystallized specimens (Figure 6).

The DSC data on the specimens thermocycled in the MT temperature range suggest that crystallization technique has the strongest effect on the MT parameters. Electropulse treatment provides for a higher MT enthalpy which is in agreement with the higher intensity of the B19 phase reflections in the X-ray diffraction patterns of the specimens subjected to this type of treatment (Figure 6). This is caused by the fact that rapid crystallization hinders the formation of detrimental Ti-Cu phases during the decomposition of the B2 austenite phase [27]. Furthermore, the characteristic MT temperatures in the dynamically crystallized specimens are higher, probably due to the noticeably larger grain sizes. The effect of treatment in the amorphous state on the MT parameters is less strong. One can note that the MT temperature range in the specimen which was subjected to tensile deformation in the amorphous state is shifted toward lower temperatures possibly due to the smaller grain sizes and less defective internal grain structure in this specimen (Figure 10b).

The goals set in this work obviously require further study. This is primarily associated with the fact that the structure of amorphous alloys obtained by alloy undercooling largely inherits the structure of the liquid phase and therefore its description should take into account density fluctuations, local neighborhood and chemical composition. Extended X-ray absorption fine structure spectroscopy (EXAFS) allows obtaining direct information on the local atomic structure since it provides data on the nearest coordination, bond lengths, degree of disorder and chemical composition of surrounding atoms [34-36]. We therefore plan studies of the TiNiCu alloy specimens containing 30 at.\% copper by EXAFS in synchrotron radiation for clarifying the dynamics of local structure and spatial distribution of local structural distortions in the alloy for the initial amorphous state, in the activated amorphous state and after crystallization by different techniques.

In addition the main feature of the TiNiCu alloys is the ability to exhibit clearly pronounced SME. It is evidently necessary to find out the effect of thermal and mechanical treatment in the amorphous state on the properties of the alloy as a functional SME material. To this end we will take into account the correlation of the structure and phase transition parameters with SME parameters in alloy specimens obtained under different conditions of amorphous state formation and crystallization.

\section{Conclusions}

The quasibinary TiNi-TiCu system alloy containing 30 at. $\% \mathrm{Cu}$ was produced by the planar flow casting technique at a melt cooling rate of about $10^{6} \mathrm{~K} / \mathrm{s}$ in the form of amorphous ribbons with a thickness of around $40 \mu \mathrm{m}$.

Melt-spun ribbons were subjected to thermal and mechanical impact in the amorphous state: isothermal annealing at $350{ }^{\circ} \mathrm{C}$ (below the glass transition temperature) for $600 \mathrm{~s}$, tensile stress along the ribbon at up to $900 \mathrm{MPa}$ and sequential exposure to isothermal annealing and tensile stress. It was found that after all types of treatment the structure of the alloy remains almost completely amorphous but the characteristic temperatures and 
enthalpy of crystallization become slightly lower. This suggests that alloy treatment in the amorphous state can accelerate crystallization by reducing its activation energy and produces regions in which crystallization may occur at lower temperatures.

Crystallization of the amorphous state activated by the thermal and/or mechanical treatment were carried out by isothermal annealing at $500{ }^{\circ} \mathrm{C}$ for $300 \mathrm{~s}$ and electropulsing with passing a single electric current pulse with preset duration of $10 \mathrm{~ms}$.

X-ray diffraction showed that all the test specimens after isothermal and electropulse crystallization have a crystalline structure corresponding to the rhombic martensite phase $B 19$ which transforms into the $B 2$ austenite phase upon heating. The diffraction patterns of the specimens vary but slightly for different impacts, nevertheless electropulse treatment leads to an increase in the intensity of the $B 19$ phase reflections.

SEM and TEM studies revealed that isothermal crystallization of the alloys both in the initial and activated amorphous states produces a sufficiently homogeneous submicrocrystalline structure with an average grain size of about $0.4-1.0 \mu \mathrm{m}$ with nanosized plate-like and subgrain structures In the meantime electropulse crystallization dramatically changes the morphology of the alloy structure by producing a bimorphic structure of large 4-6 $\mu \mathrm{m}$ sized grains and 2-3 $\mu \mathrm{m}$ high columnar crystals in the vicinity of the surface with the large crystals with a subgrain structure. It was established that the thermal impact in the amorphous state before crystallization treatment provides specimens with larger grain sizes whereas mechanical impact in the amorphous state produces equiaxed and finer grains as compared with other treatment types. The internal subgrain structure is finer in the specimens which were subjected to tensile treatment in the amorphous state.

The DSC data demonstrated the strong effect of crystallization technique on the martensitic transformation (MT) parameters. Electropulse treatment provides for a higher MT enthalpy by preventing the formation of detrimental Ti-Cu phases and for higher MT temperatures due to the noticeably larger grain sizes. The effect of impact in the amorphous state on the MT parameters is less strong. Nevertheless the MT temperature range in the specimen which was subjected to tensile deformation in the amorphous state is shifted toward lower temperatures possibly due to the smaller grain sizes and less defective internal grain structure in this specimen.

It is planned to further study of the effect of thermal and/or mechanical impact in the amorphous state on the local crystalline structure and shape memory behavior of the rapidly quenched $\mathrm{TiNiCu}$ alloy containing 30 at.\% copper.

Author Contributions: Conceptualization, A.S. and N.S.; methodology, N.S., N.T. and N.A.; investigation, N.S., I.Z., N.T. and N.A.; resources, A.S.; writing-original draft preparation, A.S. and N.T.; writing-review and editing, A.S. and N.S.; supervision, A.S. All authors have read and agreed to the published version of the manuscript.

Funding: This research was funded by the Russian Scientific Foundation, project no. 19-12-00327.

Institutional Review Board Statement: Not applicable.

Informed Consent Statement: Not applicable.

Acknowledgments: TEM study was carried out on the equipment of the Center Collective Use "Materials Science and Metallurgy" with the financial support of the Russian Federation represented by the Ministry of Education and Science (no. 075-15-2021-696).

Conflicts of Interest: The authors declare no conflict of interest.

\section{References}

1. Lecce, L.; Concilio, A. Shape Memory Alloy Engineering for Aerospace, Structural and Biomedical Applications; Butter-worth-Heinemann: Oxford, UK, 2015.

2. Hartl, D.J.; Lagoudas, D.C. Aerospace applications of shape memory alloys. Proc. IMechE Part G J. Aerosp. Eng. 2007, 221, 535-552. [CrossRef]

3. Janke, L.; Czaderski, C.; Motavalli, M.; Ruth, J. Applications of shape memory alloys in civil engineering structures-Overview, limits and new ideas. Mater. Struct. 2005, 38, 578-592. 
4. Mohd Jani, J.; Leary, M.; Subic, A.; Gibson, M.A. A review of Shape Memory Alloy research, applications and opportunities. Mater. Des. 2013, 56, 1078-1113. [CrossRef]

5. Stachiv, I.; Alarcon, E.; Lamac, M. Shape Memory Alloys and Polymers for MEMS/NEMS Applications: Review on Recent Findings and Challenges in Design, Preparation, and Characterization. Metals 2021, 11, 415. [CrossRef]

6. Rao, A.; Srinivasa, A.R.; Reddy, J.N. Design of Shape Memory Alloy (SMA) Actuators; Springer: Cham, Switzerland, 2015.

7. Kohl, M.; Ossmer, H.; Gueltig, M.; Megnin, C. SMA Foils for MEMS: From Material Properties to the Engineering of Microdevices. Shape Mem. Superelasticity 2018, 4, 127-142. [CrossRef]

8. Nespoli, A.; Besseghini, S.; Pittaccio, S.; Villa, E.; Viscuso, S. The high potential of shape memory alloys in developing miniature mechanical devices: A review on shape memory alloy mini-actuators. Sens. Actuators A Phys. 2010, 158, 149-160. [CrossRef]

9. Nam, T.H.; Saburi, T.; Nakata, Y.; Shimizu, K. Shape memory characteristics and lattice deformation in Ti-Ni-Cu alloys. Mater. Trans. JIM 1990, 31, 1050-1056. [CrossRef]

10. Nam, T.H.; Saburi, T.; Kawamura, Y.; Shimizu, K. Cu content dependence of shape memory characteristics in Ti-Ni-Cu alloys. Mater. Trans. JIM 1990, 31, 959-967. [CrossRef]

11. Kang, S.W.; Lim, Y.M.; Lee, Y.H.; Moon, H.J.; Kim, Y.W.; Nam, T.H. Microstructures and shape memory characteristics of a Ti-20Ni-30Cu (at.\%) alloy strip fabricated by the melt overflow process. Scr. Mater. 2010, 62, 71-74. [CrossRef]

12. Senkovskiy, B.V.; Usachov, D.Y.; Fedorov, A.V.; Vilkov, O.Y.; Shelyakov, A.V.; Adamchuk, V.K. Electronic structure of Ti-Ni alloys: An XPS and NEXAFS study. J. Alloys Compd. 2012, 537, 190-196. [CrossRef]

13. Ishida, A.; Sato, M. Microstructure and shape memory behaviour of annealed $\mathrm{Ti}_{51.5} \mathrm{Ni}_{(48.5-\mathrm{x})} \mathrm{Cu}_{\mathrm{x}}(\mathrm{x}=6.5-20.9)$ thin films. Philos . Mag. 2007, 87, 5523-5538. [CrossRef]

14. Shelyakov, A.V.; Sitnikov, N.N.; Borodako, K.A.; Khabibullina, I.A.; Dyadechko, A.A. Structure and functional properties of rapidly quenched TiNiCu alloys with high copper contents. J. Phys. Conf. Ser. 2021, 1758, 012036. [CrossRef]

15. Sitnikov, N.; Shelyakov, A.; Rizakhanov, R.; Mitina, N.; Khabibullina, I. The effect of copper on structure of TiNiCu melt-spun ribbons. Mater. Today Proc. 2017, 4, 4680-4684. [CrossRef]

16. Liu, Y. Mechanical and thermomechanical properties of a $\mathrm{Ti}_{50} \mathrm{Ni}_{25} \mathrm{Cu}_{25}$ melt spun ribbon. Mater. Sci. Eng. A 2003, 354, $286-291$. [CrossRef]

17. Shelyakov, A.V.; Sevryukov, O.N.; Sitnikov, N.N.; Borodako, K.A.; Khabibullina, I.A. Formation of structure of TiNiCu alloys with high copper content upon producing by planar flow casting. J. Phys. Conf. Ser. 2020, 1686, 012056. [CrossRef]

18. Tong, Y.X.; Liu, Y.; Xie, Z.L. Characterization of a rapidly annealed $\mathrm{Ti}_{50} \mathrm{Ni}_{25} \mathrm{Cu}_{25}$ melt-spun ribbon. J. Alloys Compd. 2008, 456, 170-177. [CrossRef]

19. Chang, S.H.; Wu, S.K.; Kimura, H. Annealing effects on the crystallization and shape memory effect of $\mathrm{Ti}_{50} \mathrm{Ni}_{25} \mathrm{Cu}_{25} \mathrm{melt}_{-5 p u n}$ ribbons. Intermetallics 2007, 15, 233-240. [CrossRef]

20. Shelyakov, A.; Sitnikov, N.; Khabibullina, I.; Borodako, K.; Sevryukov, O. Shape Memory Behavior of Rapidly Quenched High-copper TiNiCu Alloys. U. Porto J. Eng. 2021, 7, 2-10. [CrossRef]

21. Shelyakov, A.; Sitnikov, N.; Saakyan, S.; Menushenkov, A.; Rizakhanov, R.; Korneev, A. Study of Two-Way Shape Memory Behavior of Amorphous-Crystalline TiNiCu Melt-Spun Ribbons. Mater. Sci. Forum 2013, 738-739, 352-356. [CrossRef]

22. Sitnikov, N.N.; Shelyakov, A.V.; Khabibullina, I.A.; Visotina, E.A. The microstructure of rapidly quenched TiNiCu ribbons crystallized by isothermal and electropulse treatments. IOP Conf. Ser. Mater. Sci. Eng. 2020, 770, 012088. [CrossRef]

23. Shelyakov, A.V.; Sitnikov, N.N.; Khabibullina, I.A.; Sundeev, R.V.; Sevryukov, O.N. Specifics of Crystallization of Amorphous TiNiCu Alloys with High Concentrations of Copper. Phys. Solid State 2020, 62, 937-941. [CrossRef]

24. Ishida, A.; Sato, M. Microstructures of crystallized Ti51.5Ni48.5-xCux ( $\mathrm{x}=23.4-37.3)$ thin films. Intermetallics 2011, 19, 900-907. [CrossRef]

25. Zhu, R.F.; Tang, G.Y.; Shi, S.Q.; Fu, M.W.; Gromov, V.E. Effect of electropulsing treatment on the microstructure and superelasticity of TiNi alloy. Appl. Phys. A-Mater. 2013, 111, 1195-1201. [CrossRef]

26. Matveeva, N.M.; Pushin, V.G.; Shelyakov, A.V.; Bvkovskii, Y.A.; Volkova, S.V.; Kraposhin, V.S. Effect of conditions of crystallization of amorphous TiNi-TiCu alloys on structure and shape memory. Phys. Met. Metallogr. 1997, 83, 626-632.

27. Shelyakov, A.; Sitnikov, N.; Khabibullina, I.; Tabachkova, N.; Fominski, V.; Andreev, N. Effect of high-rate annealing on microstructure, martensitic transformation and shape memory behavior of TiNiCu melt-spun ribbons. Mater. Lett. 2019, 248, 48-51. [CrossRef]

28. Sheng, Y.; Hua, Y.; Wang, X.; Zhao, X.; Chen, L.; Zhou, H.; Wang, J.; Berndt, C.C.; Li, W. Application of High-Density Electropulsing to Improve the Performance of Metallic Materials: Mechanisms, Microstructure and Properties. Materials 2018, 11, 185. [CrossRef]

29. Chang, L.; Grummon, D.S. Structure evolution in sputtered thin films of $\mathrm{Ti}_{\mathrm{x}}(\mathrm{Ni}, \mathrm{Cu})_{1-\mathrm{x}} \mathrm{I}$ : Diffusive transformations. Philos. Mag. 1997, A76, 163-189. [CrossRef]

30. Glezer, A.M.; Shurygina, N.A. Amorphous-Nanocrystalline Alloys, 1st ed.; CRC Press: Boca Raton, FL, USA, 2017.

31. Edwards, S.F.; Mehta, A. Dislocations in amorphous materials. J. Phys. France 1989, 50, 2489-2503. [CrossRef]

32. Argon, A.S. Plastic deformation in metallic glasses. Acta Metall. 1979, 27, 47-58. [CrossRef]

33. Spaepen, F. Microscopic Mechanism for Steady-State Inhomogeneous Flow in Metallic Glasses. Acta Metall. 1977, 25, 407-415. [CrossRef]

34. Goryczka, T.; Karolus, M.; Ochin, P.; Morawiec, H. Martensites in NiTi and NiTiCu alloys-Structure of melt spun $\mathrm{Ti}_{50} \mathrm{Ni}_{25} \mathrm{Cu}_{25}$ ribbons studied by X-ray diffraction. J. Phys. France 2001, 11, 345-350. 
35. Zarinejad, M.; Liu, Y.; Liu, T.; White, T.; Yang, P.; Chen, Q. Evolution of local atomic structure in a melt-spun $\mathrm{Ti}_{50} \mathrm{Ni}_{25} \mathrm{Cu}_{25} \mathrm{shape}$ memory alloy during crystallization. Philos. Mag. 2011, 91, 404-420. [CrossRef]

36. Chernysheva, O.; Shelyakov, A.; Sitnikov, N.; Veligzhanin, A.; Borodako, K.; Sundeev, R. Local atomic and crystal structure of rapidly quenched TiNiCu shape memory alloys with high copper content. Mater. Lett. 2021, 285, 129104. [CrossRef] 